\title{
Sunk Investments Lead to Unpredictable Prices
}

\author{
By George J. Mailath, Andrew Postlewaite, and Larry Samuelson*
}

\begin{abstract}
We study transactions that require investments before trading in a competitive market, when forward contracts fixing the transaction price are absent. We show that, despite the market being perfectly competitive and subject to arbitrarily little uncertainty, the inability to jointly determine investment levels and prices may make it impossible for buyers and sellers to predict the prices at which they will trade, leading to inefficient levels of investment and trade. (JEL D40, D50)
\end{abstract}

A couple must decide whether to take a vacation in the Caribbean or to sacrifice the vacation to save money in anticipation of some day buying a house. This is essentially an investment decision for which they need to determine the relevant returns, a problem complicated by the fact that they do not know what housing prices will be when they are ready to buy.

In a world of complete markets, the couple could simultaneously choose the house they wanted and the amount they would save. But in the absence of a forward market, they face significant uncertainty about what kind of house they will be able to afford, or indeed, whether they will be able to afford any house. This uncertainty about future prices can lead to inefficient investments. A couple that regularly skimps on current consumption will have suffered in vain if housing prices end up so high that they do not buy, and conversely there may be families that would have saved had they been able to forecast a realized price that is lower than expected. Current owners of houses face a symmetric problem. Some owners will save for retirement in anticipation of continuing to live in their house. Particularly high prices may induce such an owner to sell, with the realized capital gain prompting regret at having saved as much as he did. Other owners will be disap-

\footnotetext{
* Mailath: Department of Economics, 3718 Locust Walk, University of Pennsylvania, Philadelphia, PA 19104 (e-mail: gmailath@econ.upenn.edu); Postlewaite: Department of Economics, 3718 Locust Walk, University of Pennsylvania, Philadelphia, PA 19104 (e-mail: apostlew@econ.upenn.edu); Samuelson: Department of Economics, University of Wisconsin, 1180 Observatory Drive, Madison, WI 53706 (e-mail: larrysam@ssc.wisc.edu). We thank the National Science Foundation (Grants SES-0095768, SES-9911219, and SES-0241506) for financial support.
}

pointed when unexpectedly small capital gains force consumption sacrifices.

The difficulty is that current investments cannot be coordinated with future transactions. It is no surprise that significant uncertainty about the fundamentals of an economy can give rise to future price uncertainty that, coupled with a lack of forward markets, leads to inefficient outcomes. We show that, even with arbitrarily small amounts of exogenous aggregate uncertainty, the inability to condition investments on future prices leads to nontrivial unpredictability of prices and inefficient outcomes.

The aggregate uncertainty in our model arises from perturbations to the supply curve and has the property that, conditional on investments, small amounts of uncertainty imply only small variations in the level of market-clearing trade. As a consequence, agents can predict with some confidence whether they will be engaging in the future transactions. However, even small amounts of uncertainty lead to large variations in the price of these transactions, so that the price cannot be predicted with confidence.

We discuss our model in terms of a housing market where investments are labor inputs that determine buyers' and sellers' incomes, with houses being traded in the subsequent market. Higher anticipated housing prices lead those intending to buy a house to make larger investments and those intending to sell a house to reduce their investments. However, the driving force behind the inefficiencies, the separation of investment decisions and future discrete market transactions, is not unique to the housing market. There is a potential for such an inefficiency whenever people make current investment decisions whose returns depend upon future prices that are not currently contractible. For example, 
the market for professional services such as lawyers is characterized by this type of separation. Sellers must invest in a legal education before entering the market, while buyers must invest in infrastructure, including a client base, before hiring lawyers. In each case, the optimal investment will depend upon whether the agent plans to trade, and at what price.

Section I describes the preferences of buyers and sellers in the economy in which buyers and sellers make investments and meet in a market to trade a good. We examine an Arrow-Debreu economy in Section II where perfectly competitive buyers and sellers simultaneously choose their investments and subsequent transactions. This economy has complete markets and its unique equilibrium is efficient, independent of the degree of uncertainty.

Section III introduces the economy in which investments must be made before the housing market opens. While the optimal investment depends upon the market participation of the agent and the price of the trade if he does participate, the market outcome is determined only after the investments are chosen. When choosing their investments, the buyers and sellers cannot write contracts contingent on the subsequent price. Since our interest is in the properties of the equilibria of such an economy with small amounts of uncertainty, Section IV analyzes the limiting economy where there is no uncertainty. The critical properties of the economy with uncertainty-in particular, the extreme inelasticity of ex post demand and supply when uncertainty is small-are most easily understood in the stark form in which they appear in the certain economy: discontinuities in inverse ex post demand and supply.

The Arrow-Debreu supply and demand curves are not relevant in the housing market after investments have been sunk. Ex post, agents on both sides of the market evaluate the desirability of participating in the housing market without the flexibility of altering investments. They will not change their ex ante participation decisions if prices only differ somewhat from the price they expected. As a result, ex post supply and demand share a common point of discontinuity and their intersection does not determine the price of housing. An interval of prices clears the ex post market, including the unique price that induces efficient $e x$ ante investments. This indeterminacy of ex post market-clearing prices leads to a multiplicity of equilibria. In addition to a deterministic equilibrium (with correct price expectations and efficient investments), there are "sunspot" equilibria, all of which have correct price expectations, but have random prices and inefficient investments and trade.

Section V returns to the economy with uncertainty. In this economy, coincident discontinuities in inverse ex post demand and supply curves occur with zero probability. Ex post market-clearing prices are now unambiguously determined, but fluctuate in response to fluctuations in supply. As these fluctuations become arbitrarily small, the inverse demand and supply functions become more inelastic and the equilibria approach inefficient, random-price (or sunspot) equilibria of the certain economy. In particular, the deterministic equilibrium is not approached by any sequence of equilibria of the uncertain economies.

Section VI discusses the results, including the sense in which considering the certain economy as the limiting case of the uncertain economies clarifies the nature of the seemingly arbitrary restrictions on ex post price determination that the standard equilibrium concept (deterministic rational expectations with market clearing) imposes in the certain economy. We also defer to Section VI a discussion of related work.

\section{Buyers and Sellers}

There is a continuum of buyers, uniformly distributed on $[0,1]$. Buyer $i \in[0,1]$ has utility function over labor input and expenditure on a house

$$
u(\ell, p h)+(1-i) h,
$$

where $\ell \in \Re_{+}$is the buyer's choice of labor, $p$ is the price of a house, and $h \in\{0,1\}$ is a binary variable indicating whether the buyer has purchased a house (with $h=1$ indicating purchase). Buyers are heterogeneous with higher indexed buyers having lower utility for a house. We assume $u: \Re_{+}^{2} \rightarrow \Re$ is $C^{3}$ and strictly concave, with $u_{2}<0$ and $u_{12}>0 .{ }^{1}$ To ensure interior solutions, we assume $u_{1}(0,0)>0$ and $\lim _{\ell \rightarrow \infty} u(\ell, p)=-\infty$ for all $p$. It is perhaps most natural to assume that

\footnotetext{
${ }^{1}$ A special case is separable preferences $u(\ell, p h)=$ $\hat{u}(\ell-p h)-\hat{c}(\ell)$, where the concave function $\hat{u}$ captures the utility from nonhousing consumption and the convex function $\hat{c}(\cdot)$ captures the disutility of effort.
} 
all agents have access to rental housing at a common price, with $p$ being the excess over this price required to purchase housing, and with agents differing in the premium they put on ownership. The utility $u(\ell, 0)$ is then the utility of an agent who rents rather than owns.

We denote by $\ell^{*}(p)$ the optimal level of labor when a buyer buys a house $(h=1)$ for price $p$ :

$$
\begin{aligned}
\ell *(p) & =\underset{\ell}{\operatorname{argmax}} u(\ell, p)+(1-i) \\
& =\underset{\ell}{\operatorname{argmax}} u(\ell, p) .
\end{aligned}
$$

Note that $\ell^{*}(p)$ does not depend upon the buyer's index $i$ and is increasing in $p$, since increasing the housing price decreases the buyer's consumption (conditional on purchasing a house) and hence increases the marginal utility of consumption, inducing the buyer to increase his investment in the production of income. Note also that $\ell^{*}(0)$ is the optimal level of labor when a buyer does not buy a house.

There is similarly a continuum of sellers, uniformly distributed on $[0,1]$. In addition, there is an atom of size $\varepsilon \omega$ of sellers with index 0 , where $\omega$ is uniformly distributed on $[0,1]$ and $\varepsilon<1$. If $\varepsilon>0$, the economy has exogenous aggregate uncertainty. The economy without uncertainty is given by setting $\varepsilon=0$, in which case, $\omega$ can be interpreted as a sunspot (or extrinsic uncertainty, since it does not directly affect the economy). Seller $j \in[0,1]$ has utility function over his labor input and the proceeds from selling his house

$$
v(e, p(1-h))+j h,
$$

where $e \in \mathfrak{R}_{+}$is the seller's choice of labor, $p$ is the price of the house, $h \in\{0,1\}$ is a binary variable indicating whether the potential seller has sold his house ( $h=1$ indicates that the seller has not sold) and $v: \mathfrak{R}_{+}^{2} \rightarrow \mathfrak{R}$ is $C^{3}$, with $v_{2}>0$, $v$ strictly concave, and $v_{12}<0$. We assume $v_{1}(0,0)>0$ and $\lim _{e \rightarrow \infty} v(e, p)=-\infty$ for all $p$.

Let $e^{*}(p)$ be the optimal level of labor when a seller sells his house for a price $p$ :

$$
e^{*}(p)=\underset{e}{\operatorname{argmax}} v(e, p) .
$$

The optimal labor choice depends upon the anticipated price (in a decreasing manner), but not the sellers' index. Note that $e^{*}(0)$ is the optimal level of labor when a seller does not sell the house.

\section{The Arrow-Debreu Equilibrium}

We first suppose that investments and subsequent transactions can be determined simultaneously. This gives rise to what we call the Arrow-Debreu world, so called because agents have access to a complete set of markets in which current and all future transactions are simultaneously determined.

Buyer $i$ strictly prefers to buy a house at price $p$ [with investment $\ell^{*}(p)$ ] rather than not buy a house [with investment $\ell *(0)$ ] if and only if

$$
u(\ell *(p), p)+(1-i)>u(\ell *(0), 0),
$$

so (ignoring boundary conditions for the moment) the Arrow-Debreu (A-D) demand curve is given by $D(p)$, where

$$
D(p)=1+u(\ell *(p), p)-u(\ell *(0), 0) .
$$

Seller $j$ strictly prefers to sell his house at price $p$ [and investment $e^{*}(p)$ ] rather than not sell the house if and only if

$$
v\left(e^{*}(p), p\right)>v\left(e^{*}(0), 0\right)+j,
$$

so (again ignoring boundary conditions) the A-D supply curve is given by $S_{\varepsilon}(p, \omega)$, where

$$
S_{\varepsilon}(p, \omega)=v\left(e^{*}(p), p\right)-v\left(e^{*}(0), 0\right)+\varepsilon \omega .
$$

Note that if $\varepsilon=0$, A-D supply is independent of $\omega$.

The A-D demand is continuous and strictly decreasing $\left[D^{\prime}(p)=u_{2}(\ell *(p), p)<0\right]$, and A-D supply is continuous and strictly increasing $\left[S_{\varepsilon}^{\prime}(p, \omega)=v_{2}\left(e^{*}(p), p\right)>0\right]$. As a result, the Arrow-Debreu market-clearing price $p_{\varepsilon}^{*}(\omega)$ is given by the unique price solving

$$
D(p)=S_{\varepsilon}(p, \omega) \text {. }
$$

Associated with the price $p_{\varepsilon}^{*}(\omega)$ is the marginal buyer

$$
\begin{aligned}
i\left(p_{\varepsilon}^{*}(\omega)\right) \equiv & 1+u\left(\ell^{*}\left(p_{\varepsilon}^{*}(\omega)\right), p_{\varepsilon}^{*}(\omega)\right) \\
& -u\left(\ell^{*}(0), 0\right)
\end{aligned}
$$

and marginal seller 


$$
\begin{aligned}
j\left(p_{\varepsilon}^{*}(\omega)\right) \equiv & v\left(e^{*}\left(p_{\varepsilon}^{*}(\omega)\right), p_{\varepsilon}^{*}(\omega)\right) \\
& -v\left(e^{*}(0), 0\right)=i\left(p_{\varepsilon}^{*}(\omega)\right)-\varepsilon \omega .
\end{aligned}
$$

The set of buyers who actually purchase is $\left[0, i\left(p_{\varepsilon}^{*}(\omega)\right)\right]$ and the set of sellers who actually sell is $\left[0, j\left(p_{\varepsilon}^{*}(\omega)\right)\right]$. The efficient outcome is for buyers and sellers in the intervals $\left[0, i\left(p_{\varepsilon}^{*}(\omega)\right)\right]$ and $\left[0, j\left(p_{\varepsilon}^{*}(\omega)\right)\right]$ to undertake investments $\ell^{*}\left(p_{\varepsilon}^{*}(\omega)\right)$ and $e^{*}\left(p_{\varepsilon}^{*}(\omega)\right)$ and to trade the good at price $p_{\varepsilon}^{*}(\omega)$, with other buyers and sellers choosing investments $\ell^{*}(0)$ and $e^{*}(0)$.

Note that, in the economy with complete markets, as the exogenous uncertainty vanishes, the market-clearing quantity and price as well as investments converge to the market-clearing quantity, price, and investments of the economy without uncertainty. In other words, small amounts of exogenous uncertainty do not have a large impact on equilibrium prices, quantities, or investments.

\section{Sunk Investments}

Suppose now that buyers and sellers make their labor investments before entering the housing market. In particular, the investments are made before $\omega$ is realized. We assume that buyers and sellers have common expectations over the price that will clear the housing market when making their investments, and we will be concerned with equilibria in which these expectations are correct. The market-clearing price depends upon the investments of the buyers and sellers through their reservation prices. When making their investment decisions, buyers and sellers take into account their expectations of not only the price of housing, but also whether, given the price, they will participate in the housing market.

\section{A. Reservation Prices}

We first describe the ex post market, i.e., the market for housing, given investment decisions. The following lemma is immediate.

LEMMA 1: Buyers are characterized by an ex post reservation price $p_{i}(\ell)$ that is differentiable, strictly increasing in $\ell$ and strictly decreasing in $i$. Sellers are characterized by an ex post reservation price $p_{j}(e)$ that is differentiable, strictly decreasing in $e$, and strictly increasing in $j$.
Definition 1: Suppose buyer $i$ has chosen labor $L_{i}$, seller $j$ has chosen effort $E_{j}$, and that the induced functions $L:[0,1] \rightarrow \Re_{+}$and $E:[0,1] \rightarrow$ $\Re_{+}$are measurable. Ex post demand and supply are given by

$$
D(p, L)=\lambda\left\{i \mid u\left(L_{i}, p\right)+1-i \geq u\left(L_{i}, 0\right)\right\},
$$

and

$$
\begin{aligned}
& S_{\varepsilon}(p, E, \omega) \\
& \quad=\lambda\left\{j \mid v\left(E_{j}, p\right) \geq v\left(E_{j}, 0\right)+j\right\}+\varepsilon \omega,
\end{aligned}
$$

where $\lambda$ is Lebesgue measure.

Since $S_{\varepsilon}(0, E, \omega)=\varepsilon \omega$ and $D(0, L)=1$ for any $E$ and $L$, ex post market clearing must occur at a strictly positive price (recall $\varepsilon<1$ ). Since $S_{\varepsilon}(p, E, \omega)>0$ for all $p$, ex post market clearing must occur with a strictly positive level of transaction. We will see that the results are unaffected if we alter the assumption that indifferent agents trade.

\section{B. Equilibrium with Sunk Investments}

Since prices may (and when $\varepsilon>0$, will) depend upon the realized value of $\omega \in[0,1]$, we need to allow for random prices in the ex post market. Suppose $p:[0,1] \rightarrow \mathfrak{R}_{+}$is the price function. Buyer $i$ chooses the labor investment before $\omega$, and so the housing price $p(\omega)$, is realized. The purchase decision, on the other hand, occurs after $\omega$ is realized. The optimal level of labor is thus a value of $\ell$ maximizing expected payoffs ${ }^{2}$

$$
\int_{0}^{1} \max \{u(\ell, p(\omega))+(1-i), u(\ell, 0)\} d \omega .
$$

Seller $j$ 's optimal effort is similarly a value of $e$ maximizing

$$
\int_{0}^{1} \max \{v(e, p(\omega)), v(e, 0)+j\} d \omega .
$$

Our next lemma (proved in the Appendix) characterizes optimal investments, showing that

\footnotetext{
${ }^{2}$ It is possible that there are several maximizers.
} 
agents who are more likely to own a house choose larger labor investments. Consequently, optimal labor investments are measurable functions of buyer and seller indices, and ex post demand and supply are well defined.

LEMMA 2: Fix a price function $p$. The buyer's optimal labor choice, $L^{*}$, is a (weakly) decreasing function of the buyer index $i$. The seller's optimal labor choice, $E^{*}$, is a (weakly) increasing function of the seller index $j$.

A rational expectations equilibrium is a price function such that, when correctly predicted, each price in the support of the distribution clears the ex post market:

Definition 2: A rational expectations equilibrium is a price function, $p^{*}:[0,1] \rightarrow \mathfrak{R}_{+}$, and labor and effort choices, $L^{*}$ and $E^{*}$, such that, for all $\omega \in[0,1]$,

$$
D\left(p^{*}(\omega), L^{*}\right)=S_{\varepsilon}\left(p^{*}(\omega), E^{*}, \omega\right),
$$

and buyers and sellers are choosing labor and effort optimally, given $p^{*}$.

\section{The Certain Economy}

We first analyze the certain economy, i.e., $\varepsilon=0$. In this case, the realizations of $\omega$ are simply sunspots. If the price is a nontrivial function of the realizations of $\omega$, then the price is random in the absence of intrinsic uncertainty.

When $\varepsilon=0$, it will be convenient to occasionally suppress the underlying uncertainty over $\omega$ and focus directly on the uncertainty over prices. Let $\gamma$ denote the probability measure on $\mathfrak{R}_{+}$describing the (possibly random) price that appears in the ex post market. A rational expectations equilibrium for the certain economy can be described as the triple $(\gamma, L, E)$. The support of $\gamma$, denoted $\operatorname{supp}(\gamma)$, is the smallest closed set assigned probability 1 by $\gamma$. The smallest price that can be realized under $\gamma$ is given by $p(\gamma)=\min \{p \in \operatorname{supp}(\gamma)\}$, while the largest price that can be realized under $\gamma$ is given by $\bar{p}(\gamma)=\max \{p \in \operatorname{supp}(\gamma)\}$. If there is no uncertainty about prices, then $p(\gamma)=\bar{p}(\gamma)=$ $p$ and $\gamma$ places all of its mass on that single price $p$. If price is a nontrivial function of $\omega$, then $p(\gamma)<\bar{p}(\gamma)$.
Definition 3: A rational expectations equilibrium of the certain economy $(\varepsilon=0)$ is a sunspot equilibrium if the price distribution $\gamma^{*}$ is not degenerate $\left[p\left(\gamma^{*}\right)<\bar{p}\left(\gamma^{*}\right)\right]$, otherwise it is deterministic.

A sunspot equilibrium yields a variety of market-clearing prices. However, every realized price implies the same quantity of trade. If not, there are two prices, $p<p^{\prime}$, that both clear the market with different volumes of trade. If the volume of trade at price $p$ is greater, it must be that the supply that is forthcoming at the lower price is higher, a contradiction. Similarly, if the volume is lower at price $p$, it must be that fewer buyers purchase at the lower price, also a contradiction. We summarize this in the following lemma, and give the proof in the Appendix.

LEMMA 3: Suppose $\varepsilon=0$. Fix a rational expectations equilibrium $(\gamma, L, E)$. Every realized market price yields the same quantity of trade. There is an index $i(\gamma)$ such that all buyers $i<i(\gamma)$ are willing to trade at any price in $[p(\gamma), \bar{p}(\gamma)]$, while no buyer $i>i(\gamma)$ is willing to trade at any price in the interval. For $i<$ $i(\gamma)$, the optimal labor choice is

$$
L_{i}=\ell *(\gamma) \equiv \underset{\ell}{\operatorname{argmax}} \int_{\Re_{+}} u(\ell, p) d \gamma(p),
$$

while for $i>i(\gamma)$, the optimal choice is $L_{i}=$ $\ell^{*}(0) \equiv \operatorname{argmax}_{\ell} u(\ell, 0)$.

Similarly, there is an index $j(\gamma)=i(\gamma)$ such that all sellers $j<j(\gamma)$ are willing to trade at any price in $[p(\gamma), \bar{p}(\gamma)]$, while no seller $j>j(\gamma)$ is willing to do so. For $j<j(\gamma)$, the optimal effort choice is

$$
E_{j}=e^{*}(\gamma) \equiv \underset{e}{\operatorname{argmax}} \int_{\Re_{+}} v(e, p) d \gamma(p),
$$

while for $j>j(\gamma)$, the optimal choice is $E_{j}=$ $e^{*}(0) \equiv \operatorname{argmax}_{e} v(e, 0)$.

The property that all buyers planning to purchase a house choose the same labor investment (with a similar statement for buyers planning to not purchase and for sellers), an implication of the separability of the buyer's index in the utility function, is convenient but not important for 


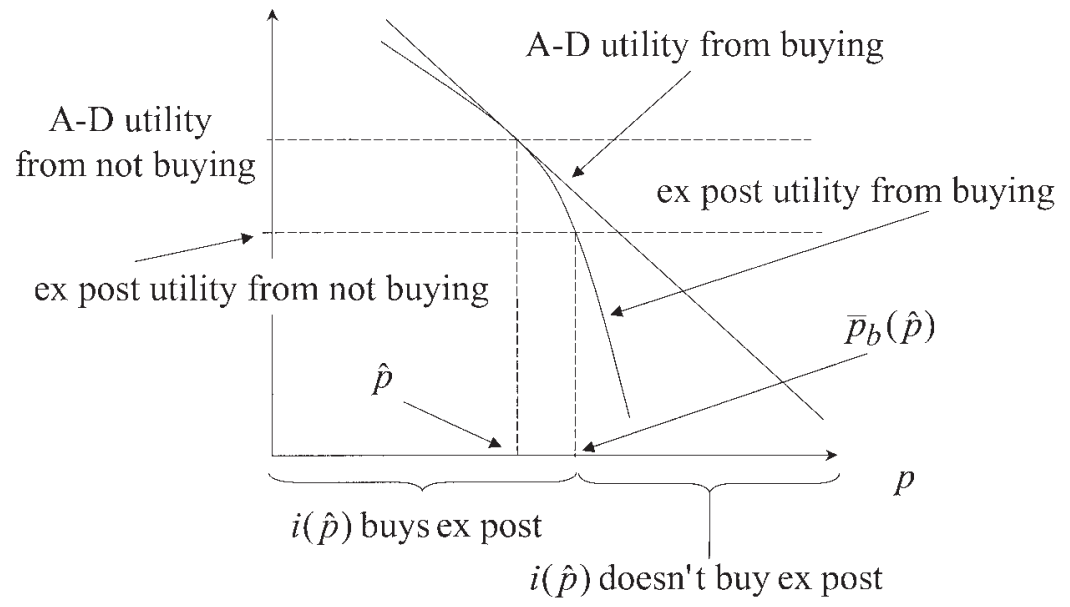

Figure 1. Ex Post Utilities from Buying And Not Buying a House for Buyer $i(\hat{p})$ Who Anticipated the Deterministic Price $\hat{p}$ And Chose $\ell *(\hat{p})$

Notes: The ex post utility from buying is $u\left(\ell^{*}(\hat{p}), p\right)+1-i(\hat{p})$, while the ex post utility from not buying is $u(\ell *(\hat{p}), 0)$. The utility from buying in the Arrow-Debreu world (or more simply, the A-D utility) is $u(\ell *(p), p)+1-i(\hat{p})$, while the A-D utility from not buying is $u\left(\ell^{*}(0), 0\right)$.

the results. The critical property is that the labor investments of buyers planning to purchase is larger by some fixed amount than those of buyers planning not to purchase.

\section{A. Discontinuities}

We now argue that for the certain economy, the inverse ex post demand function has a discontinuity at the marginal buyer. The key observation is that, in contrast to the ArrowDebreu demand, the ex post demand is determined conditional on investments being fixed at the levels taken before entering the housing market. A buyer who can adjust his investment will react differently to variations in price than will a buyer whose investment level is fixed. From Lemma 3, buyers fall into two groups: low-index buyers who undertake a large investment in anticipation of purchasing a house, and high-index buyers who undertake a small investment while planning not to purchase a house. This will imply that the ex post reservation price schedule jumps at the marginal buyer. Similarly, a discontinuity will arise in sellers' reservation prices, and moreover, these discontinuities will both occur at the ex post marketclearing quantity of trade.
Consider the case of a predicted deterministic housing price, $\hat{p}$. In this case, we write $i(\hat{p})$ for the marginal buyer rather than $i(\gamma)$, and so on. Figure 1 shows the ex post utilities for buyer $i(\hat{p})$ after choosing investment $\ell *(\hat{p})$, the optimal investment should he buy a house. The buyer's indifference balances owning a house, and making the optimal investment conditional on ownership, with not owning a house and making the optimal investment conditional on not purchasing. However, when the buyer enters the housing market, his investment is sunk. The comparison is now between owning a house, having made the investment that is optimal given ownership, and not owning a house and living with the sunk investment that is suboptimal given that he has not purchased a house. Not buying the house is now less attractive, and as a result, the buyer's ex post reservation price $\bar{p}_{b}(\hat{p}) \equiv p_{i(\hat{p})}\left(\ell^{*}(\hat{p})\right)$, is higher than his reservation price in the Arrow-Debreu world, $\hat{p}$.

Now suppose the marginal buyer $i(\hat{p})$ invests $\ell *(0)$ on the presumption that he will not purchase a house, illustrated in Figure 2. Now purchasing a house is less attractive than in the Arrow-Debreu economy, given the sunk investment, and hence his ex post reservation price $p_{b}(\hat{p})$ is lower than his reservation price in the Arrow-Debreu world, $\hat{p}$. 


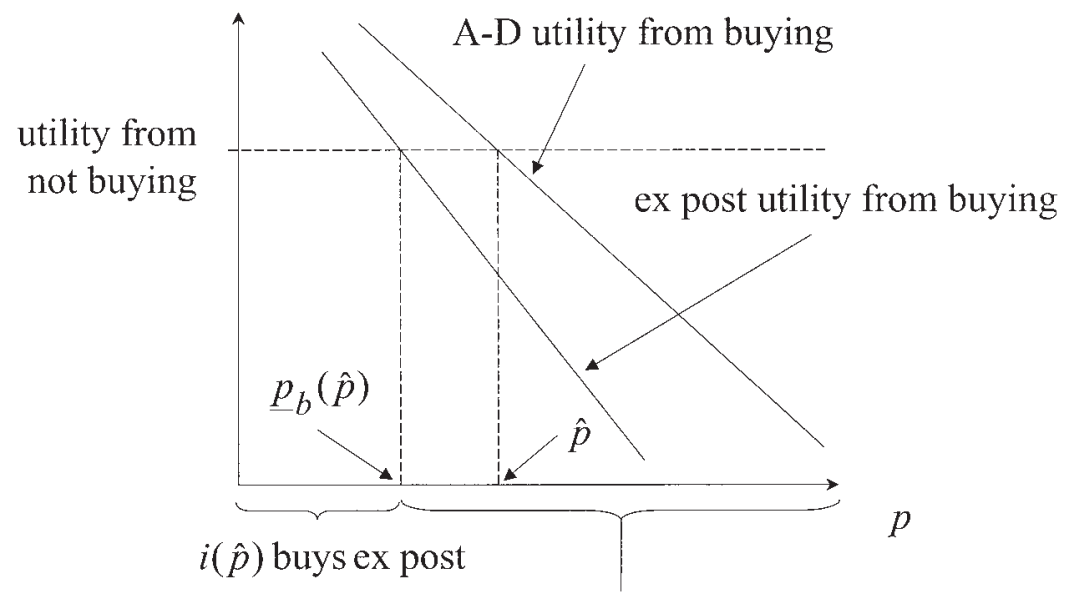

$i(\hat{p})$ doesn't buy ex post

Figure 2. Ex Post Utilities from Buying and Not Buying a House for Buyer $i(\hat{p})$ Who HAD CHOSEN $\ell *(0)$

Notes: The A-D utility from buying is $u\left(\ell^{*}(p), p\right)+1-i(\hat{p})$, while the ex post utility from buying is $u\left(\ell^{*}(0), p\right)+1-i(\hat{p})$. The utility from not buying is $u\left(\ell^{*}(0), 0\right)$.

The above discussion suggests (and Lemma 4, proved in the Appendix, confirms) that, in any rational expectations equilibrium, there is a discontinuity in inverse ex post demand at $i(\gamma)$, illustrated in Figure $3 .^{3}$

LEMMA 4: Fix a rational expectations equilibrium of the certain economy, and buyer $i(\gamma)$ and seller $j(\gamma)$ as defined in Lemma 3. Ex post demand is given by

$$
\tilde{D}(p, \gamma)=\left\{\begin{array}{r}
u(\ell *(\gamma), p)+1-u(\ell *(\gamma), 0), \\
i(\gamma), \quad \text { if } p>\bar{p}_{b}(\gamma), \\
u(\ell *(0), p)+1-u(\ell *(0), 0), \\
\text { if } p \in\left[p_{b}(\gamma), \bar{p}_{b}(\gamma)\right], \\
\text { if } p<\underline{p}_{b}(\gamma) .
\end{array}\right.
$$

${ }^{3}$ It is possible that (as drawn) the ex post reservation price for low-index buyers is below their A-D reservation price. Such a buyer cannot adjust his labor to accommodate the very high price at which he is indifferent ex post between buying a house and not. Recall that at the price expected, $\hat{p}$, the marginal buyer, $i(\hat{p})$, is indifferent in the Arrow-Debreu world between buying and not buying. Consequently, for $i(\hat{p})$, his ex post reservation price, $\bar{p}_{b}(\hat{p})$, is strictly larger than $\hat{p}$, his A-D reservation price. In contrast, the low-index buyer is eager to buy at the price $\hat{p}$.

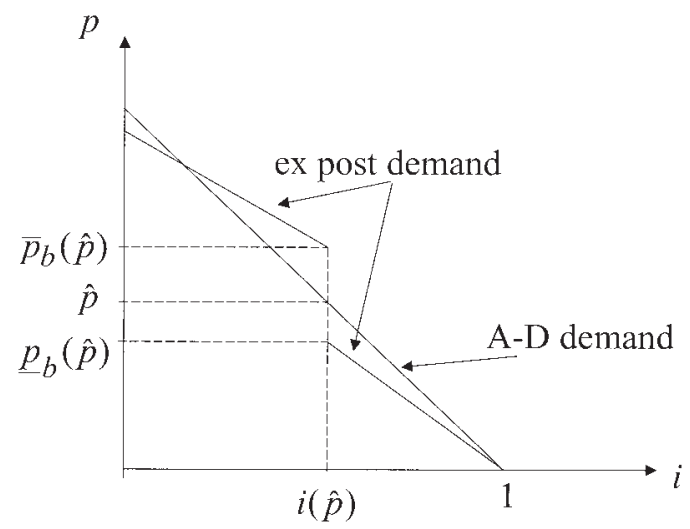

Figure 3. Inverse Demand Functions for the ArrowDebreu World and the Ex Post World With SunK Labor, When Buyers Expect the Price $\hat{p}$

If $\gamma$ is degenerate (i.e., there exists $\hat{p}$ such that $\gamma(\{\hat{p}\})=1)$, then $^{4}$

$$
\underline{p}_{b}(\gamma)<\underline{p}(\gamma)=\hat{p}=\bar{p}(\gamma)<\bar{p}_{b}(\gamma) .
$$

Ex post supply is given by

\footnotetext{
${ }^{4}$ Recall that in this case, $p_{b}(\gamma)$ and $\bar{p}_{b}(\gamma)$ were denoted $\underline{p}_{b}(\hat{p})$ and $\bar{p}_{b}(\hat{p})$ in the discussion above.
} 


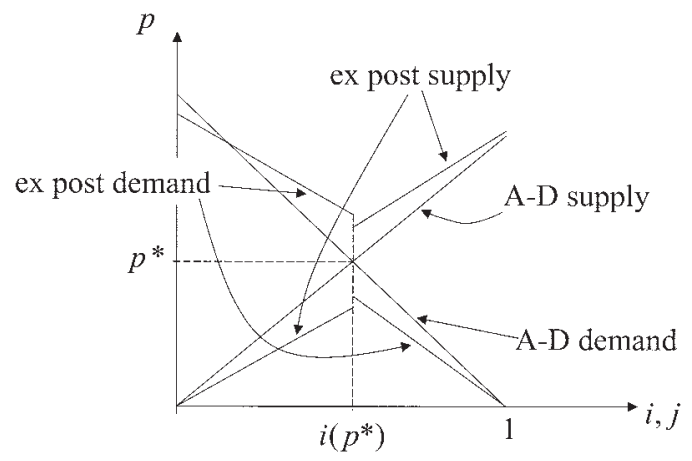

Figure 4. The Rational Expectations Equilibrium at THE ARrow-Debreu Price, $p^{*}$

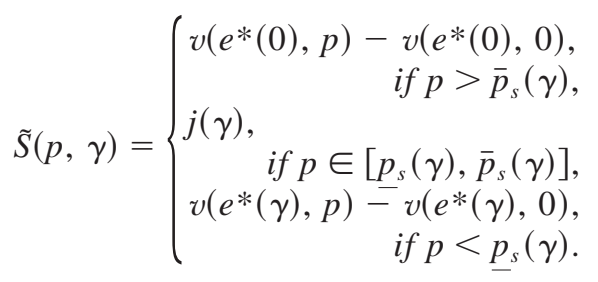

If $\gamma$ is degenerate (i.e., there exists $\hat{p}$ such that $\gamma(\{\hat{p}\})=1)$, then

$$
\underline{p_{s}}(\gamma)<\underline{p}(\gamma)=\hat{p}=\bar{p}(\gamma)<\bar{p}_{s}(\gamma)
$$

\section{B. (In)efficiency}

We have just seen that for a given specification of ex ante investments consistent with a rational expectations equilibrium, there will be many ex post market-clearing prices. An efficient equilibrium requires the ex post marketclearing process select the "correct" price, namely the Arrow-Debreu equilibrium price $p *$. Figure 4 illustrates the efficient deterministic rational expectations equilibrium.

If a distribution of prices $\gamma$ is a sunspot equilibrium, it cannot be the case that all prices in the support of $\gamma$ are greater than the ArrowDebreu equilibrium price $p^{*}$. Such a distribution would induce a strictly greater supply of houses than the deterministic price $p^{*}$, but no greater demand, and hence markets would not clear. Similarly, all prices in the support of $\gamma$ cannot be less than $p^{*}$. We summarize these observations in the next proposition, the proof of which is left to the Appendix.

PROPOSITION 1: (i) There is a unique deterministic rational expectations equilibrium of the certain economy, given by the Arrow-Debreu market-clearing price $p^{*}$. This equilibrium is efficient. (ii) In any sunspot equilibrium $\gamma$ of the certain economy,

$$
\underline{p}(\gamma)<p^{*}<\bar{p}(\gamma)
$$

and

$$
i(\gamma)<i\left(p^{*}\right)
$$

and hence any sunspot equilibrium is inefficient.

The existence of an efficient equilibrium in which price $p^{*}$ appears in the ex post market is obvious. Proposition 3 below shows that sunspot equilibria also exist.

In every equilibrium, agents correctly anticipate ex post prices. However, investments and trade are efficient only when this anticipation is deterministic. In a sunspot equilibrium, while the efficient market-clearing price is in the convex hull of the support of prices, there is inefficiently little trade. Two additional sources of inefficiency arise, namely the agents' inability to choose a single investment that is optimal for every possible ex post price and the direct utility costs of random prices in a strictly concave utility function.

We argue in Section V that only the sunspot equilibria are robust. Consequently, the inefficiencies of this proposition will be the rule rather than the exception.

\section{Effectively Completing the Market}

Our main result is that if agents must make investment decisions in anticipation of future economic decisions on which they cannot contract, then investments are likely to be inefficient. The inefficiency, of course, is due to the (assumed) incompleteness of markets. From a descriptive point of view, the incompleteness is very reasonable: there is no futures market in houses that allows potential buyers to lock in a set price, nor is it possible for a student contemplating law school to sign an employment contract commencing on his graduation from law school. It is not surprising that some of these markets fail to be active, due (for example) to moral hazard considerations.

However, in order to ensure efficiency, it is not necessary to have such forward contracts. 
For example, suppose agents can buy and sell a security that pays to the owner of the security an amount equal to the price of housing. Suppose buyer $i$ has purchased $x$ units of the security ( $x<0$ if the agent has sold the security) at $\theta$ per unit, has chosen $\ell$, and makes housing decision $h$. Then, the buyer's utility is

$$
u(\ell, p h-x(p-\theta))+(1-i) h,
$$

since the income available for nonhousing consumption is $\ell+x p-p h-x \theta^{5}$ Similarly, if seller $j$ has purchased $x$ units of the security at $\theta$ per unit, has chosen $e$, and makes housing decision $h$, the seller's utility is

$$
v(\ell, p(1-h)-x(p-\theta))+j h .
$$

We assume the security is in zero net supply. If $\gamma$ is the probability distribution over prices, market clearing in the securities market then requires $\theta=\int p d \gamma(p)$.

Consequently, in the economy with a securities market, in any sunspot equilibrium, the investment choices and quantity are efficient: Suppose $\gamma$ is a sunspot price distribution. Observe first that (by the argument in the proof of Lemma 3 ) there is a marginal buyer $i(\gamma)$, such that all buyers $i<i(\gamma)$ buy with probability one, and buyers $i>i(\gamma)$ do not buy with probability one (a similar statement holds for sellers). Then all buyers $i<i(\gamma)$ buy one unit of the security and face no price uncertainty, effectively paying the price $\theta$. Since the buyer $i>i(\gamma)$ is not buying the house, it is optimal for him not to buy any of the security. Consequently, $i(\gamma)$ is indifferent between buying the house at price $\theta$, and not buying. Similarly, seller $j(\gamma)$ is indifferent between selling the house at price $\theta$, and not selling. Since the index of the marginal buyer and seller for the same deterministic price agree, the marginal buyer is $i\left(p^{*}\right)$, and so $\theta=$ $p^{*}$, the deterministic rational expectations price.

While it is not surprising that forward markets fail to be active, the possibility of securities that condition on the price of housing seems more reasonable. For example, the London firm City Index allows investors to bet on house

\footnotetext{
${ }^{5}$ The buyer can replicate the net returns of the security by buying one call option with strike price $\theta$, selling one put option with strike price $\theta$, and selling or buying the house involved in the executed option.
}

prices. ${ }^{6}$ These property futures are available on the average house price for several regions in England and Wales, as well as for a number of London boroughs and more specific property types such as flat/maisonette. Robert J. Shiller (2003) argues that the information and technological advances will increasingly make such markets possible.

Similar securities could presumably arise in other markets requiring investment before trade, such as the market for lawyers. While there are clear moral hazard issues that prevent forward contracting, moral hazard would not be a barrier to a market similar to the City Index. Individuals could buy and sell securities that paid an amount equal to the average salary of lawyers in a given city, or an amount equal to the average starting salary of lawyers.

Such securities must be carefully designed if they are to eliminate completely the type of uncertainty and attendant inefficiency that is at the heart of our analysis. The difficulty is that houses and lawyers tend to be quite heterogeneous commodities. Houses come in different locations and sizes and with different amenities, while lawyers differ in their specialties, skills, experience, and personal networks. ${ }^{7}$ The market for housing or attorneys is thus a collection of (possibly overlapping) submarkets for particular types of houses or lawyers. A buyer or seller would like to purchase not simply a security pegging the average price in the market, but a security pegging the price in the submarket relevant for that buyer or seller. Unfortunately, it is difficult to specify such a submarket ex ante, and ex post specifications give rise to moral hazard problems. Who could specify in advance just which houses comprise the set of suitable alternatives when one is ready to purchase a house in some unknown number of years? But without such an agreement, the owner of a security that pays the average purchase price of a suitable house has an ex post incentive to exaggerate the required characteristics.

We could surmount some of these difficulties

\footnotetext{
${ }^{6}$ More information can be found at www.cityindex. co.uk. We thank Hyun Song Shin for bringing City Index to our attention.

${ }^{7}$ To simplify the exposition, our model assumes that housing is homogenous. Modifying the model to incorporate such heterogeneity would not qualitatively alter the analysis (see Section VI).
} 
with more appropriately designed financial markets. Shiller and Allan N. Weiss (1999), for example, advocate the development of a market to insure homeowners against losses in the values of their homes. To be completely effective, such a policy would presumably also have to eliminate the appreciation risk. However, it will be quite difficult to overcome the moral hazard problems involved in insuring the future salaries of potential lawyers before they enter law school, while heterogeneous characteristics will again make it difficult to completely insure the price of a home that one may anticipate buying, or a lawyer that one may anticipate hiring, some time in the future.

\section{The Uncertain Economy}

We begin our analysis of the economy with exogenous uncertainty by studying ex post price formation, given an arbitrary price function. In Lemmas 5 and $6, L^{*}$ and $E^{*}$ denote the implied optimal labor and effort choices, while Lemma 7 describes the implied ex post market clearing.

LEMMA 5: The buyer's optimal reservation price $p_{i}\left(L_{i}^{*}\right)$ is strictly decreasing in $i$. The seller's reservation price $p_{j}\left(E_{j}^{*}\right)$ is strictly increasing in $j$.

\section{PROOF:}

We consider the buyer. For $i>i^{\prime}, L_{i}^{*} \leq L_{i^{\prime}}^{*}$ (from Lemma 2), and so Lemma 1 implies $p_{i}\left(L_{i}^{*}\right) \leq p_{i}\left(L_{i^{\prime}}^{*}\right)<p_{i^{\prime}}\left(L_{i^{\prime}}^{*}\right)$.

We have a similar monotonicity result for $e x$ post demand and supply:

LEMMA 6: Ex post demand, $D\left(p, L^{*}\right)$, and supply, $S_{\varepsilon}\left(p, E^{*}, \omega\right)$, are respectively decreasing and increasing continuous functions of $p$. Hence, the inverse ex post demand and ex post supply curves are strictly monotonic.

\section{PROOF:}

Since the reservation price $p_{i}(\ell)$ is strictly increasing in $\ell$ and strictly decreasing in index $i$, ex post demand, given by

$$
D\left(p, L^{*}\right)=\lambda\left\{i: p_{i}\left(L_{i}^{*}\right) \geq p\right\},
$$

is then continuous in $p$ because $p_{i}\left(L_{i}^{*}\right)$ is strictly decreasing in $i$ (Lemma 5). A similar argument applies to supply.

As a result, any movement in ex post supply must change the market-clearing price:

LEMMA 7: For almost all $\omega$, the ex post market-clearing price $p(\omega)$ is unique. The ex post market-clearing price is strictly decreasing in $\omega$.

\section{PROOF:}

Since the inverse ex post demand and supply (for each value of $\omega$ ) are strictly monotonic, they have only a countable number of discontinuities. Consequently, the set of $\omega$ for which there is a mutual discontinuity in the inverse ex post demand and supply is also countable. Hence, for almost all $\omega$, the intersection of inverse ex post demand and supply occurs when at least one of demand or supply is continuous, and so the ex post market-clearing price $p(\omega)$ is uniquely determined.

Let $\omega^{\prime}>\omega$ and let $D(p(\omega), L)=S_{\varepsilon}(p(\omega), E, \omega)$. Then $S_{\varepsilon}\left(p(\omega), E, \omega^{\prime}\right)>S_{\varepsilon}(p(\omega), E, \omega)$ and hence $D(p(\omega), L)<S_{\varepsilon}\left(p(\omega), E, \omega^{\prime}\right)$. Given that $D(p, L)$ is continuous and decreasing in $p$ while $S_{\varepsilon}\left(p, E, \omega^{\prime}\right)$ is continuous and increasing in $p$ (Lemma 6), the value $p\left(\omega^{\prime}\right)$ solving $D\left(p\left(\omega^{\prime}\right), L\right)=S_{\varepsilon}\left(p\left(\omega^{\prime}\right), E, \omega^{\prime}\right)$ must satisfy $p\left(\omega^{\prime}\right)<p(\omega)$.

Finally (the proof is in the Appendix):

PROPOSITION 2: A rational expectations equilibrium exists for every $\varepsilon>0$.

\section{A. Inefficient Investments}

We are now in a position to present our main result: Price uncertainty remains as the exogenous uncertainty becomes negligible. To obtain some intuition, consider the inverse supply and demand curves shown in Figure 5, where these correspond to the realized demand and supply for a particular value of $\omega$. The important feature here is that both curves become very steeply sloped near the quantity $i^{\prime}$. Buyers and sellers with indices much smaller than $i^{\prime}$ are quite certain that they will trade the good. Their investments thus show very little variation in their indices, and hence their reservation prices show relatively little variation in indices. The same is true of buyers and sellers with much larger valuations, who are virtually certain that 


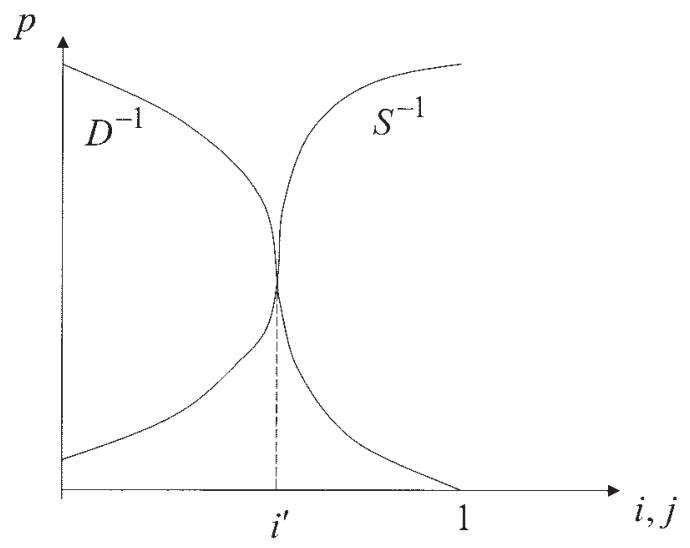

Figure 5. Ex Post Inverse Demand and Supply Curves WITH Random EX ANTE SupPly

they will not trade the good. However, as indices increase from slightly below $i^{\prime}$ to slightly above $i^{\prime}$, the probability of trading the good drops from nearly one to nearly zero. As a result, investments vary tremendously within this range of indices and hence so do reservation prices.

These steep segments in inverse ex post supply and demand create the potential for small variations in supply to create large variations in the ex post price. Hence, we can expect significant price volatility, even with relatively little noise in supply. As $\varepsilon$ gets small, the range of indices over which inverse ex post supply and demand are (ever more) steeply sloped becomes quite small, as the ex post supply and demand curves converge to those of the deterministic case shown in Figures 3-4. The result is convergence to a sunspot equilibrium of the deterministic market.

PROPOSITION 3: (i) Suppose $\varepsilon \rightarrow 0$. Then any converging subsequence of equilibrium prices $p_{\varepsilon}$ converges weakly to a sunspot equilibrium distribution of the certain economy. (ii) The allocation induced by the limiting prices $\lim _{\varepsilon \rightarrow 0} p_{\varepsilon}$ is inefficient.

Notice that this proposition establishes the existence of sunspot equilibria for the deterministic market.

The proof of the second statement follows immediately from the first statement and the observation that the limit of equilibria of the perturbed markets must be an equilibrium of the certain market. Proposition 1 has established that any such equilibrium featuring a nondegenerate distribution of prices is inefficient.

We provide a sketch of the argument of the first statement, leaving the details to the Appendix. Suppose that a sequence of equilibrium prices converged to a deterministic price, $\bar{p}$. First note that for almost all $\omega$, the marketclearing price is uniquely determined by the intersection of ex post demand and supply (Lemma 7). For each such $\omega$, there is either a marginal buyer or seller (or both). Without loss of generality, we can restrict attention to sequences where the marginal agents are always buyers. In fact, there is a convergent sequence of pairs of buyers, $\left\{\left(i_{1}(\varepsilon), i_{2}(\varepsilon)\right)\right\}_{\varepsilon}$ with a corresponding sequence of pairs of states $\left\{\left(\omega_{1}(\varepsilon), \omega_{2}(\varepsilon)\right)\right\}_{\varepsilon}$ such that $i_{k}(\varepsilon)$ is the marginal buyer in state $\omega_{k}(\varepsilon), k=1$ and $2, i_{1}(\varepsilon)<i_{2}(\varepsilon)$, and $\omega_{1}(\varepsilon)+1 / 4$ $<\omega_{2}(\varepsilon)$. In other words, the two buyers are marginal in two very different states. Consequently, the probability that $i_{1}(\varepsilon)$ buys a house exceeds by at least one-quarter the probability that $i_{2}(\varepsilon)$ buys house. This in turn implies that $i_{1}(\varepsilon)$ 's optimal investment (and so reservation price) is bounded away from $i_{2}(\varepsilon)$ 's optimal investment (and so reservation price). But, along the sequence of states we are considering, equilibrium prices are determined by the reservation prices of the marginal buyers. The convergence of equilibrium prices to a deterministic price then implies that $i_{1}(\varepsilon)$ 's reservation price cannot be bounded away from $i_{2}(\varepsilon)$ 's reservation price, a contradiction.

Again, the inefficiency takes three forms. First, the quantity of trade is inadequate. Secondly, the inability to predict price leads to investments that are optimal "on average," and hence suboptimal for many realized prices. Finally, the strict concavity of utility in price causes the price variability to reduce utility.

\section{Discussion and Related Literature}

We have assumed for convenience only that the good traded in the ex post market is homogeneous. In practice, houses are heterogeneous-locations are unique, room arrangement and decoration vary, and so on. Heterogeneous houses would be priced hedonically, and potential buyers (and sellers) would presumably differ in the prices at which they anticipate trading 
and in their investment levels. Nevertheless, as long as there is a (positive) lower bound on the price of houses facing each agent, there will be a gap in the investments chosen by those who expect to transact and those who do not. ${ }^{8}$ This gap will result in a discontinuity in the ex post supply and demand functions as in our analysis, and consequently, the multiplicity of ex post market-clearing prices that are the source of the potentially inefficient investments.

More generally, a gap in ex ante investments, between those planning to trade in the ex post market and those planning to not trade, will exist whenever there is a nontrivial difference between trading the good and not doing so. This will be true of the housing market as long as the financial implications of renting and owning housing are not nearly identical, and similarly will be true of labor markets as long as the skills required to be a lawyer or doctor or plumber are not nearly identical. This gap in ex ante investments will lead to discontinuities in ex post supply and demand whenever the investments are at least partially sunk. This will be the case in housing markets if one cannot reverse past financial decisions, and will be true in labor markets if one cannot reverse past education decisions. Hence, if one cannot retroactively unconsume a vacation, or retroactively obtain a medical rather than law degree, then we can expect ex post discontinuities.

For the housing interpretation of our model, risk aversion on the part of agents is a necessary ingredient of the inefficiency. It is the concavity of the utility function that requires differing $e x$ ante investments for different ex post housing prices. For interpretations of the model in which the investments are made by firms, the concavity need not be due to risk aversion, but might represent diminishing marginal productivity in the sector not subject to future price uncertainty.

Our results also shed light on the seemingly arbitrary restrictions on ex post price determination that the standard equilibrium concept (deterministic rational expectations with market clearing) imposes in the certain economy. While a deterministic rational expectations equilibrium of the

\footnotetext{
${ }^{8}$ It is not necessary that the cheapest house be more costly than the most expensive rental alternative. Rather, the key feature of the market is that for any particular buyer, the relevant rental and purchase options differ sufficiently as to induce different investments.
}

certain economy exists and is efficient, there are many ex post market-clearing prices, and so the efficient equilibrium requires a seemingly magical selection from the set of ex post market-clearing housing prices. It could be argued that earlier investment decisions coordinate the ex post market on the only price consistent with equilibrium in those preceding decisions. ${ }^{9}$ However, this argument uses the equilibrium concept to impose strong restrictions (in particular, the coordination on the Arrow-Debreu price) on the unmodeled ex post price determination process. Moreover, as we have seen, these restrictions may be inconsistent with any equilibrium of close-by plausible economies.

As in our paper, the hold-up literature (see, e.g., Sanford J. Grossman and Oliver D. Hart, 1986) focuses on the difference between ex ante and ex post reservation prices due to sunk investments. If two parties are to divide the surplus from a joint venture but the division is to take place subsequent to an investment by one party, the investing party may well be willing to accept a division ex post that he would reject ex ante. The classical hold-up problem treats the case in which there is a value to the investment only within the relationship between the two parties, and hence the investment is said to be relationship specific. Because of the investing agent's resulting vulnerability to being "held up" after investing, inefficient investment is the norm.

One might hypothesize that the inefficiency of investment is a consequence of the market power of the noninvesting party and that sufficient competition in the ex post market would eliminate the inefficiency. Our model and results suggest that this is not necessarily the case. The investments in our model are not relationship specific - there is a continuum of agents on each side of the market, all of whom are perfect substitutes in a housing transaction, regardless of the investment an agent might make. The inefficiency of investment does depend on the divergence between ex ante and ex post reservation prices: once an agent's investment is

\footnotetext{
${ }^{9}$ The properties of an equilibrium in a game, or the mere existence of an equilibrium, may depend upon how one selects from the multiple equilibria of a subgame. For example, Felix Kübler and Herakles Polemarchakis (2004) present an example in which existence in an overlappinggenerations economy requires a subgame equilibriumselection rule that is inconsistent with Markov perfection.
} 
sunk, he is vulnerable to unexpected price movements in the housing market. Agents' investments are thus decision specific, in that an agent's anticipated utility from the investment depends on carrying out the planned transaction. Our result is that decision-specific investments are likely to be inefficient.

Franklin Allen and Douglas Gale (2003) also demonstrate the robustness of sunspot equilibria. They analyze a banking model in which there are multiple equilibria, some exhibiting bank runs and some without, when there is no aggregate uncertainty. They show that only the equilibria exhibiting bank runs are limits of equilibria for economies with positive but vanishingly small real uncertainty. ${ }^{10}$

The sunspot equilibria in our paper and in Allen and Gale (2003) differ qualitatively from the sunspot equilibria that have been studied in a number of other papers. The early sunspot literature was, at least partly, motivated by Keynes' notion of "animal spirits." This was the notion that some events- "sunspots"-might have real effects in an economy, even if all

\footnotetext{
${ }^{10}$ Rodolfo Manuelli and James Peck (1992) examine a model in which sunspot equilibria are robust, in the sense of being limits of equilibria of perturbed economies, but do not show that only sunspot equilibria are limits of perturbed economies.
}

agents in that economy knew that the sunspot event was orthogonal to economic fundamentals. This might happen because any individual agent might behave differently when the event occurred than otherwise simply because he expected other agents to do so. Thus, it can be rational for all agents to change their behavior upon the occurrence of an event that all know is irrelevant. The consequence is randomness in an economy with no intrinsic uncertainty.

Fundamental to the literature that captures this notion of sunspots is coordination among the agents in the economy. This aspect of coordination is absent from our model: there is no extraneous event that agents observe and coordinate on. Different housing prices in the second period in our model do not come from different agent behavior in the first period, but instead stem from the indeterminacy of marketclearing prices from their fixed first-period behavior. ${ }^{11}$ In addition, every realization of the sunspot variable leads to the same quantity of trade in the housing market. Despite this absence of an effect on the allocation of housing, the financial implications of random prices ensure that investments are inefficient.

\footnotetext{
${ }^{11}$ Similarly, in Allen and Gale (2003), the sunspot equilibria do not depend on coordinated agent behavior.
}

\section{APPENDIX}

\section{PROOF OF LEMMA 2:}

We prove this only for buyers; the sellers are dealt with similarly. Since buyers are following a reservation price strategy in the housing market (Lemma 1), we view buyer $i$ as choosing $\ell$ and $p$, with $p$ being the reservation price for the housing decision given by

$$
h(p, \omega)= \begin{cases}1, & \text { if } p(\omega) \leq p \\ 0, & \text { otherwise }\end{cases}
$$

Defining $\rho(p) \equiv \operatorname{Pr}\{p(\omega) \leq p\}$, we let $U_{i}: \mathfrak{R}_{+} \times \mathfrak{K}_{+} \rightarrow \mathfrak{R}_{+}$be the function identifying buyer $i$ 's expected payoff from the choice of $\ell$ and $p$ :

$$
U_{i}(\ell, p) \equiv \rho(p) \mathbb{E}\{u(\ell, p(\omega))+(1-i) \mid p(\omega) \leq p\}+(1-\rho(p)) u(\ell, 0) .
$$

Note that given any $p$, the same value of $\ell$ maximizes (A1) for all $i$.

Suppose $i>i^{\prime}$. The optimal choices of $p$ for the two buyers are $p_{i}^{*} \equiv p_{i}\left(L_{i}^{*}\right)$ and $p_{i^{\prime}}^{*} \equiv p_{i^{\prime}}\left(L_{i^{\prime}}^{*}\right)$, respectively. This implies

$$
U_{i}\left(L_{i}^{*}, p_{i}^{*}\right) \geq U_{i}\left(L_{i^{\prime}}^{*}, p_{i^{\prime}}^{*}\right)
$$

and 


$$
U_{i^{\prime}}\left(L_{i}^{*}, p_{i}^{*}\right) \leq U_{i^{\prime}}\left(L_{i^{\prime}}^{*}, p_{i^{\prime}}^{*}\right)
$$

That is,

$$
\begin{aligned}
& \rho\left(p_{i}^{*}\right) \mathbb{E}\left\{u\left(L_{i}^{*}, p(\omega)\right)+(1-i) \mid p(\omega) \leq p_{i}^{*}\right\}+\left(1-\rho\left(p_{i}^{*}\right)\right) u\left(L_{i}^{*}, 0\right) \\
& \geq \rho\left(p_{i^{\prime}}^{*}\right) \mathbb{E}\left\{u\left(L_{i^{\prime}}^{*}, p(\omega)\right)+(1-i) \mid p(\omega) \leq p_{i^{\prime}}^{*}\right\}+\left(1-\rho\left(p_{i^{\prime}}^{*}\right)\right) u\left(L_{i^{\prime}}^{*}, 0\right)
\end{aligned}
$$

and

$$
\begin{aligned}
& \rho\left(p_{i^{\prime}}^{*}\right) \mathbb{E}\left\{u\left(L_{i^{\prime}}^{*}, p(\omega)\right)+\left(1-i^{\prime}\right) \mid p(\omega) \leq p_{i^{\prime}}^{*}\right\}+\left(1-\rho\left(p_{i^{\prime}}^{*}\right)\right) u\left(L_{i^{\prime}}^{*}, 0\right) \\
& \geq \rho\left(p_{i}^{*}\right) \mathbb{E}\left\{u\left(L_{i}^{*}, p(\omega)\right)+\left(1-i^{\prime}\right) \mid p(\omega) \leq p_{i}^{*}\right\}+\left(1-\rho\left(p_{i}^{*}\right)\right) u\left(L_{i}^{*}, 0\right) .
\end{aligned}
$$

Adding these two inequalities and canceling common terms yields

$$
\rho\left(p_{i^{\prime}}^{*}\right)\left(i-i^{\prime}\right) \geq \rho\left(p_{i}^{*}\right)\left(i-i^{\prime}\right),
$$

and since $i>i^{\prime}$,

$$
\rho\left(p_{i^{\prime}}^{*}\right) \geq \rho\left(p_{i}^{*}\right)
$$

i.e.,

$$
\operatorname{Pr}\left\{p(\omega) \leq p_{i^{\prime}}^{*}\right\} \geq \operatorname{Pr}\left\{p(\omega) \leq p_{i}^{*}\right\}
$$

We now argue that $L_{i}^{*} \leq L_{i^{\prime}}^{*}$. Note [from (A1)] that if the measure describing ex post prices $\gamma$ has atoms, $\partial U_{i}\left(L_{i}^{*}, p_{i}\left(\ell^{\prime}\right)\right) / \partial \ell$ will not be continuous in $\ell^{\prime}$. Nonetheless, we can apply the envelope theorem of Paul Milgrom and Ilya Segal (2002, Theorem 3) as follows: The function $U_{i}\left(\ell, p_{i}(\ell)\right)$ is left- and right-hand differentiable at all interior $\ell$. Since $L_{i}^{*}$ is optimal for $i$,

$$
0 \leq D_{L} U_{i}\left(L_{i}^{*}, p_{i}\left(L_{i}^{*}\right)\right)
$$

where $D_{L}$ denotes the total left-hand derivative. ${ }^{12}$ Since $p_{i}(\ell)$ is a continuous increasing function of $\ell$, we have, where $\rho\left(p_{i}^{*-}\right) \equiv \lim _{p \uparrow p_{i}^{*}} \operatorname{Pr}\{p(\omega) \leq p\}$ [and Milgrom and Segal (2002, Theorem 3) gives the first equality]:

$$
\begin{aligned}
0 \leq & D_{L} U_{i}\left(L_{i}^{*}, p_{i}\left(L_{i}^{*}\right)\right) \\
= & \lim \left[\rho\left(p_{i}(\ell)\right) \mathbb{E}\left\{u_{1}\left(L_{i}^{*}, p(\omega)\right) \mid p(\omega) \leq p_{i}(\ell)\right\}+\left(1-\rho\left(p_{i}(\ell)\right)\right) u_{1}\left(L_{i}^{*}, 0\right)\right] \\
& \ell \uparrow L_{i}^{*} \\
= & \rho\left(p_{i}^{*-}\right) \lim \mathbb{E}\left\{u_{1}^{*}\left(L_{i}^{*}, p(\omega)\right) \mid p(\omega) \leq p\right\}+\left(1-\rho\left(p_{i}^{*-}\right)\right) u_{1}\left(L_{i}^{*}, 0\right) \\
& \quad \rho\left(p_{i}^{*}-\right) w\left(L_{i}^{*}, p_{i}^{*-}\right)+\left(1-\rho\left(p_{i}^{*-}\right)\right) u_{1}\left(L_{i}^{*}, 0\right)
\end{aligned}
$$

12 That is,

$$
D_{L} U_{i}\left(L_{i}^{*}, p_{i}\left(L_{i}^{*}\right)\right)=\lim _{\ell \uparrow L_{i}^{*}}\left\{U_{i}\left(L_{i}^{*}, p_{i}\left(L_{i}^{*}\right)\right)-U_{i}\left(\ell, p_{i}(\ell)\right)\right\} /\left(L_{i}^{*}-\ell\right) .
$$


[where $w(\ell, p) \equiv \mathbb{E}\left\{u_{1}(\ell, p(\omega)) \mid p(\omega) \leq p\right\}$. Moreover, since $L_{i^{\prime}}^{*}$ is optimal for $i^{\prime}$,

$$
0 \geq D_{R} U_{i}\left(L_{i^{\prime}}^{*}, p_{i^{\prime}}\left(L_{i^{\prime}}^{*}\right)\right),
$$

where $D_{R}$ denotes the total right-hand derivative. Since $\rho(p)$ is continuous from the right, we have [again using Milgrom and Segal (2002, Theorem 3) for the first equality],

$$
\begin{aligned}
0 \geq & D_{R} U_{i}\left(L_{i^{\prime}}^{*}, p_{i^{\prime}}\left(L_{i^{\prime}}^{*}\right)\right) \\
= & \lim \left[\rho\left(p_{i^{\prime}}(\ell)\right) \mathbb{E}\left\{u_{1}\left(L_{i^{\prime}}^{*}, p(\omega)\right) \mid p(\omega) \leq p_{i^{\prime}}(\ell)\right\}+\left(1-\rho\left(p_{i^{\prime}}(\ell)\right)\right) u_{1}\left(L_{i^{\prime}}^{*}, 0\right)\right] \\
= & \rho\left(p_{i^{\prime}}^{*}\right) \mathbb{E}\left\{u_{1}\left(L_{i^{\prime}}^{*}, p(\omega)\right) \mid p(\omega) \leq p_{i^{\prime}}^{*}\right\}+\left(1-\rho\left(p_{i^{\prime}}^{*}\right)\right) u_{1}\left(\ell_{i^{\prime}}^{*}, 0\right) \\
= & \rho\left(p_{i^{\prime}}^{*}\right) w\left(L_{i^{\prime}}^{*}, p_{i^{\prime}}^{*}\right)+\left(1-\rho\left(p_{i^{\prime}}^{*}\right)\right) u_{1}\left(L_{i^{\prime}}^{*}, 0\right) .
\end{aligned}
$$

Note that for all $p$ and all $\ell, \mathbb{E}\left\{u_{1}(\ell, p(\omega)) \mid p(\omega) \leq p\right\}=w(\ell, p) \geq u_{1}(\ell, 0)$. Since $\rho\left(p_{i}^{*}-\right) \leq \rho\left(p_{i}^{*}\right)$ and $w\left(L_{i}^{*}, p_{i}^{*}\right) \geq w\left(L_{i}^{*}, p_{i}^{*}-\right) \geq u_{1}\left(L_{i}^{*}, 0\right)$, (A3) implies

$$
0 \leq \rho\left(p_{i}^{*}\right) w\left(L_{i}^{*}, p_{i}^{*}\right)+\left(1-\rho\left(p_{i}^{*}\right)\right) u_{1}\left(L_{i}^{*}, 0\right) .
$$

Subtracting (A4) from (A5) gives

$$
0 \leq \rho\left(p_{i}^{*}\right) w\left(L_{i}^{*}, p_{i}^{*}\right)-\rho\left(p_{i^{\prime}}^{*}\right) w\left(L_{i^{\prime}}^{*}, p_{i^{\prime}}^{*}\right)+\left(1-\rho\left(p_{i}^{*}\right)\right) u_{1}\left(L_{i}^{*}, 0\right)-\left(1-\rho\left(p_{i^{*}}^{*}\right)\right) u_{1}\left(L_{i^{\prime}}^{*}, 0\right) .
$$

Now,

$$
w\left(\ell, p_{i^{\prime}}^{*}\right) \geq w\left(\ell, p_{i}^{*}\right)
$$

for all $\ell$ [this follows from the concavity of $u$ and (A2), since if $p_{i^{\prime}}^{*}<p_{i}^{*}$, then $\operatorname{Pr}\left\{p_{i^{\prime}}^{*}<p(\omega) \leq p_{i}^{*}\right\}=$ $0]$. En route to a contradiction, suppose $L_{i}^{*}>L_{i^{\prime}}^{*}$. The concavity of $u$ also implies, for all $p$ (including $p=0$ of course),

$$
u_{1}\left(L_{i^{\prime}}^{*}, p\right)>u_{1}\left(L_{i}^{*}, p\right)
$$

so that

$$
w\left(L_{i^{\prime}}^{*}, p_{i^{\prime}}^{*}\right)>w\left(L_{i}^{*}, p_{i^{\prime}}^{*}\right) \geq w\left(L_{i}^{*}, p_{i}^{*}\right) .
$$

Coupled with (A2), these inequalities allow us to conclude that

$$
\begin{aligned}
0> & \rho\left(p_{i}^{*}\right)\left[w\left(L_{i}^{*}, p_{i}^{*}\right)-w\left(L_{i^{\prime}}^{*}, p_{i^{\prime}}^{*}\right)\right]+\left(1-\rho\left(p_{i}^{*}\right)\right)\left[u_{1}\left(L_{i}^{*}, 0\right)-u_{1}\left(L_{i^{\prime}}^{*}, 0\right)\right] \\
& +\left(\rho\left(p_{i}^{*}\right)-\rho\left(p_{i^{\prime}}^{*}\right)\right)\left(w\left(L_{i^{\prime}}^{*}, p_{i^{\prime}}^{*}\right)-u_{1}\left(L_{i^{\prime}}^{*}, 0\right) .\right.
\end{aligned}
$$

Since the right side of this expression duplicates the right side of (A6), this is a contradiction. Thus, labor effort is a nonincreasing function of buyer index.

PROOF OF LEMMA 3:

Suppose $p^{\prime}, p^{\prime \prime} \in \operatorname{supp}(\gamma)$ and $p^{\prime}>p^{\prime \prime}$. Then $v\left(E_{j}, p^{\prime}\right)>v\left(E_{j}, p^{\prime \prime}\right)$ for any seller $j$ who has undertaken investment $E_{j}$. Hence, every seller who wants to trade at price $p^{\prime \prime}$ also wants to trade at price $p^{\prime}$. Applying a similar argument to buyers establishes that every buyer who wants to buy at 
price $p^{\prime}$ also wants to buy at price $p^{\prime \prime}$. Hence, the set of buyers (sellers) trading at price $p^{\prime \prime}$ (price $p^{\prime}$ ) is a weak superset of the set trading at price $p^{\prime}$ (price $p^{\prime \prime}$ ), i.e.,

$$
D\left(p^{\prime \prime}, L\right) \geq D\left(p^{\prime}, L\right)
$$

and

$$
S\left(p^{\prime \prime}, E\right) \leq S\left(p^{\prime}, E\right) .
$$

But $p^{\prime}$ and $p^{\prime \prime}$ both clear the market, giving $D\left(p^{\prime \prime}, L\right)=S\left(p^{\prime \prime}, E\right)$ and $D\left(p^{\prime}, L\right)=S\left(p^{\prime}, E\right)$, so the same collection of agents is willing to trade at price $p^{\prime}$ as at price $p^{\prime \prime}$. This holds for any $p \in[p(\gamma), \bar{p}(\gamma)]$. Consequently, each agent, when making his investment decision, behaves as if he knows for sure whether he will be trading.

Suppose buyer $i$ intends to buy a house. Then, the optimal labor choice is $\ell^{*}(\gamma)$ and

$$
\int_{\Re_{+}} u\left(\ell^{*}(\gamma), p\right) d \gamma(p)+(1-i) \geq \max _{\ell} u(\ell, 0) .
$$

But then any buyer $i^{\prime}<i$ should also buy and choose the same level of labor, $\ell^{*}(\gamma)$. Finally, if a buyer $i^{\prime}$ intends not to buy a house, then clearly buyer $i^{\prime}$ chooses labor of $\ell^{*}(0)<\ell^{*}(\gamma)$.

A symmetric argument holds for sellers. Hence, there will be a buyer index $i(\gamma)$ and seller index $j(\gamma)$ such that all buyers $i<i(\gamma)$ undertake the investment given by (1) and buy a house at every $e x$ post price, and all buyers $i>i(\gamma)$ do not undertake the investment, and do not buy a house at any ex post price. Similarly, sellers $j<j(\gamma)$ undertake the investment given by (2) and sell a house at every ex post price and sellers $j>j(\gamma)$ do not undertake the investment and do not sell a house at any ex post price. It is then immediate that $i(\gamma)=j(\gamma)$, since otherwise the putative equilibrium prices would not clear the ex post market.

\section{PROOF OF LEMMA 4:}

We present the argument for buyers. Consider first the case of a predicted deterministic housing price, $\hat{p}$. Recall that $i(\hat{p})$ is the marginal buyer. Buyer $i(\hat{p})$ 's reservation price after choosing investment $\ell^{*}(\hat{p})$, the optimal investment should he buy a house, is given by $\bar{p}_{b}(\hat{p}) \equiv p_{i(\hat{p})}\left(\ell^{*}(\hat{p})\right)$. Since $i(\hat{p})$ is indifferent in the Arrow-Debreu world between buying the house at $\hat{p}$ and not buying,

$$
\begin{aligned}
u\left(\ell^{*}(\hat{p}), \hat{p}\right)+1-i(\hat{p}) & =u\left(\ell^{*}(0), 0\right) \\
& >u(\ell *(\hat{p}), 0) \\
& =u\left(\ell^{*}(\hat{p}), \bar{p}_{b}(\hat{p})\right)+1-i(\hat{p}),
\end{aligned}
$$

implying

$$
\hat{p}<\bar{p}_{b}(\hat{p}) .
$$

On the other hand, buyer $i(\hat{p})$ 's reservation price after choosing investment $\ell^{*}(0)$, the optimal investment should he not buy a house, is given by $\underline{p}_{b}(\hat{p}) \equiv p_{i(\hat{p})}\left(\ell^{*}(0)\right)$. Since

$$
\begin{aligned}
u\left(\ell *(0), \underline{p}_{b}(\hat{p})\right)+1-i(\hat{p}) & =u(\ell *(0), 0) \\
& =u(\ell *(\hat{p}), \hat{p})+1-i(\hat{p}) \\
& >u\left(\ell^{*}(0), \hat{p}\right)+1-i(\hat{p})
\end{aligned}
$$


[where again the inequality is an implication of $\left.\ell^{*}(\hat{p}) \neq \ell^{*}(0)\right]$, we have

$$
\underline{p_{b}}(\hat{p})<\hat{p} .
$$

Consider now the case of predicted random prices. Suppose the marginal buyer $i(\gamma)$ chose $\ell^{*}(\gamma)$, intending to buy the house at each price $p \in \operatorname{supp}(\gamma)$ [recall that all buyers $i<i(\gamma)$ do so]. The highest price buyer $i(\gamma)$ is willing to pay is

$$
\bar{p}_{b}(\gamma) \equiv \sup \left\{p: u\left(\ell^{*}(\gamma), p\right)+1-i(\gamma) \geq u\left(\ell^{*}(\gamma), 0\right)\right\},
$$

so that ${ }^{13}$

$$
i(\gamma)=u\left(\ell^{*}(\gamma), \bar{p}_{b}(\gamma)\right)+1-u\left(\ell^{*}(\gamma), 0\right) .
$$

From Lemma $3, \bar{p}_{b}(\gamma) \geq \bar{p}(\gamma)$. Any nonmarginal buyer $i<i(\gamma)$ has also chosen $L_{i}=\ell^{*}(\gamma)$, and so has a reservation price $p_{i}$ that satisfies

$$
i=u\left(\ell *(\gamma), p_{i}\right)+1-u(\ell *(\gamma), 0),
$$

and [since $i<i(\gamma)$ ] exceeds $\bar{p}_{b}(\gamma)$.

Now, suppose the marginal buyer $i(\gamma)$ optimally chose $\ell^{*}(0)$, intending not to buy at any price $p \in$ $\operatorname{supp}(\gamma)$ [recall that all buyers $i>i(\gamma)$ do not intend to buy at any price $p \in \operatorname{supp}(\gamma)$ ]. Then, the lowest price at which that buyer is still willing not to buy is

$$
\underline{p}_{b}(\gamma) \equiv \inf \left\{p: u(\ell *(0), p)+1-i(\gamma) \leq u\left(\ell^{*}(0), 0\right)\right\},
$$

so that

$$
i(\gamma)=u\left(\ell *(0), \underline{p}_{b}(\gamma)\right)+1-u(\ell *(0), 0) .
$$

From Lemma $3, p_{b}(\gamma) \leq p(\gamma)$, and so

$$
\underline{p}_{b}(\gamma) \leq \underline{p}(\gamma) \leq \bar{p}(\gamma) \leq \bar{p}_{b}(\gamma) .
$$

Any nonmarginal buyer $i>i(\gamma)$ has also chosen $L_{i}=\ell^{*}(0)$ and so has a reservation price $p_{i}$ that satisfies

$$
i=u\left(\ell *(0), p_{i}\right)+1-u(\ell *(0), 0),
$$

and [since $i>i(\gamma)]$ is less than $\underline{p}_{b}(\gamma)$.

\section{PROOF OF PROPOSITION 1:}

First, consider deterministic equilibria. It is immediate that the ex ante market-clearing price is a rational expectations equilibrium and is efficient. It remains to show that there are no other deterministic equilibria. In any deterministic rational expectations equilibrium, every agent predicts correctly whether he will be participating in a housing transaction and chooses labor effort appropriately, and ex post, supply equals demand. So suppose some $p \neq p^{*}$ is a rational expectations equilibrium. If $p>p^{*}$, then there will be fewer intentional buyers than $i\left(p^{*}\right)$ and more intentional

\footnotetext{
${ }^{13}$ Note that when $\gamma$ is degenerate, $\bar{p}_{b}(\gamma)=\bar{p}_{b}(\hat{p})$, so that the notation is consistent. A similar comment applies to $\underline{p}_{b}(\gamma)$ below.
} 
sellers than $j\left(p^{*}\right)=i\left(p^{*}\right)$, requiring an ex post market-clearing price less than $p^{*}$, a contradiction. A similar argument rules out $p<p^{*}$.

Now consider sunspot equilibria. Suppose first that $p^{*} \geq \bar{p}(\gamma)$. Then since buyers have the option of setting $\ell=\ell^{*}\left(p^{*}\right)$ and since utility is strictly decreasing in $p$, for any buyer $i$, we have

$$
\int_{\underline{p}(\gamma)}^{\bar{p}(\gamma)} u\left(\ell^{*}(\gamma), p\right) d \gamma(p) \geq \int_{\underline{p}(\gamma)}^{\bar{p}(\gamma)} u\left(\ell^{*}\left(p^{*}\right), p\right) d \gamma(p)>u\left(\ell^{*}\left(p^{*}\right), p^{*}\right),
$$

ensuring that

$$
i(\gamma)>i\left(p^{*}\right)
$$

Similarly, for sellers we have

$$
\int_{\underline{p}(\gamma)}^{\bar{p}(\gamma)} v\left(e^{*}(\gamma), p\right) d \gamma(p)<v\left(e^{*}(\gamma), p^{*}\right) \leq v\left(e^{*}\left(p^{*}\right), p^{*}\right)
$$

giving

$$
j(\gamma)<j\left(p^{*}\right),
$$

which is a contradiction. A similar argument applies to the case of $p^{*} \leq p(\gamma)$.

Now consider the volume of trade in a sunspot equilibrium $(\gamma, L, E)$. Let $\hat{p}$ be the expected price under $\gamma$, and suppose $\hat{p} \geq p^{*}$. Then for any buyer $i$, we have

$$
\int_{\underline{p}(\gamma)}^{\bar{p}(\gamma)} u\left(\ell^{*}(\gamma), p\right) d \gamma(p)<u\left(\ell^{*}(\gamma), \hat{p}\right) \leq u\left(\ell^{*}(\hat{p}), \hat{p}\right) \leq u\left(\ell^{*}\left(p^{*}\right), p^{*}\right),
$$

where the first inequality is an application of Jensen's inequality, since $u_{22}<0$. Hence,

$$
i(\gamma)=\int_{\underline{p}(\gamma)}^{\bar{p}(\gamma)} u\left(\ell^{*}(\gamma), p\right) d \gamma(p)+1-u\left(\ell^{*}(0), 0\right)<u\left(\ell^{*}\left(p^{*}\right), p^{*}\right)+1-u\left(\ell^{*}(0), 0\right)=i\left(p^{*}\right) .
$$

If instead $\hat{p} \leq p^{*}$, we construct a similar argument with the seller.

PROOF OF PROPOSITION 2:

Optimal labor choices must fall in the intervals $[0, \bar{\ell}]$ and $\left[0, e^{*}(0)+1\right]$, where $\bar{\ell}$ is chosen sufficiently large that $\forall \ell \geq \bar{\ell}$,

$$
u(\ell, p)+1<u(\ell, 0)+1<u(\ell *(0), 0) .
$$

Define $\bar{e}=e^{*}(0)+1$. Define $\bar{p}$ as a bound on $p$ so that, for any $\ell \in[0, \bar{\ell}], u(\ell, \bar{p})+1<$ $u(0,0)$.

Now let $Y_{1}$ be the space of decreasing functions $L:[0,1] \rightarrow[0, \bar{\ell}]$. We endow $Y_{1}$ with the $L^{1}$ norm, where the measure on the domain is $\lambda$, Lebesgue measure. Let $Y_{2}$ be the space of increasing functions $E:[0,1] \rightarrow[0, \bar{e}]$. We endow $Y_{2}$ with the $L^{1}$ norm, using as the measure on the domain $\lambda_{\varepsilon}=\varepsilon \delta_{0}+\lambda$, where $\delta_{0}$ is the Dirac measure that assigns mass 1 to the point 0 . Define $Y \equiv \Upsilon_{1} \times$ $\Upsilon_{2}$ and endow $Y$ with the norm 


$$
\left\|(L, E),\left(L^{\prime}, E^{\prime}\right)\right\|=\max \left\{\int_{0}^{1}\left|L(i)-L^{\prime}(i)\right| d i, \int_{0}^{1}\left|E(j)-E^{\prime}(j)\right| d j+\varepsilon\left|E(0)-E^{\prime}(0)\right|\right\},
$$

where the final term reflects $\delta_{0}$, the atom of sellers of index zero. The set $Y$ is a subset of a metric space, and hence is compact if it is sequentially compact (Nelson Dunford and Jacob T. Schwartz, 1988, p. 21).

To establish sequential compactness, consider a sequence $\left\{\left(L_{n}, E_{n}\right)\right\}_{n=0}^{\infty} \subseteq \mathrm{Y}$. By taking subsequences, we can ensure that $\left(L_{n}, E_{n}\right)$ converges to a monotonic limit $(\hat{L}, \hat{E})$ at every rational index. Extend $\hat{L}$ (and, similarly, $\hat{E}$ ) to the reals by letting $\hat{L}\left(i^{\prime}\right)=\lim \hat{L}\left(i_{k}\right)$, where $\left\{i_{k}\right\}_{k=0}^{\infty}$ is a sequence of rationals approaching the nonrational number $i^{\prime}$ from below. Then the sequence $\left(L_{n}, E_{n}\right)$ must converge to $(\hat{L}, \hat{E})$ at any value of $i$ or $j$ at which $\hat{L}$ or $\hat{E}$ is continuous. Since $\hat{L}$ and $\hat{E}$ are monotonic, this ensures convergence at all but countably many values, ensuring that $\left(L_{n}, E_{n}\right)$ converges to $(\hat{L}$, $\hat{E})$ almost everywhere. Because each $\left(L_{n}, E_{n}\right)$ and $(\hat{L}, \hat{E})$ are bounded above by the integrable function $\max \{\bar{\ell}, \bar{e}\}$, Lebesgue's dominated convergence theorem ensures that $\left\|\left(L_{n}, E_{n}\right),(\hat{L}, \hat{E})\right\|$ converges to zero, giving sequential compactness.

We now define a function $\Theta: Y \rightarrow Y$ as follows. Fix a pair $(L, E) \in Y$. These define inverse $e x$ post demand and supply curves that are decreasing and increasing respectively, and hence each have at most countably many discontinuities. As a result, for almost all values of $\omega$, the equilibrium price $p_{\varepsilon}(\omega)$ is uniquely determined. Given this pricing function, we can determine optimal investments $\left(L^{*}, E^{*}\right)$. Lemma 2 guarantees that $\left(L^{*}, E^{*}\right)$ is in $Y$. If the mapping $\Theta$ is continuous, then since the set $Y$ is a compact, convex subset of a locally convex linear topological space, the SchauderTychonoff theorem (Dunford and Schwartz, 1988, p. 456) ensures that this function has a fixed point, which is the desired equilibrium.

It remains to show that the mapping $\Theta: Y \rightarrow Y$ is continuous. Let $\Lambda$ be the set of probability measures on $[0, \bar{p}]$, endowed with the topology of weak convergence. Then we can decompose the mapping $\Theta: Y \rightarrow Y$ into a pair of mappings from $\Theta_{1}: Y \rightarrow \Lambda$ and $\Theta_{2}: \Lambda \rightarrow \Upsilon$ so that $\Theta=\Theta_{2} \circ \Theta_{1}$.

Consider the first mapping, $\Theta_{1}$. Suppose $\left\{\left(L_{n}, E_{n}\right)\right\}_{n=0}^{\infty}$ converges to $(\hat{L}, \hat{E})$. Let $\mathcal{P}_{n}$ be the probability measure on prices generated by $\left(L_{n}, E_{n}\right)$ and let $p_{n}$ be the corresponding price function. From Lemma 7, $p_{n}$ is strictly decreasing in $\omega$. Let $\hat{\mathcal{P}}$ and $\hat{p}(\omega)$ be the analogous measure and pricing function associated with $(\hat{L}, \hat{E})$. It suffices for the weak convergence of $\mathcal{P}_{n}$ to $\mathcal{P}$ that $p_{n}(\omega)$ converges to $\hat{p}(\omega)$ at almost all continuity points of $\hat{p}$. [Suppose $p_{n} \rightarrow \hat{p}$ at almost all continuity points of $\hat{p}$, and hence a.e., since $\hat{p}$ is strictly decreasing. Let $F_{n}$ be the distribution function of prices under $p_{n}$ and $\hat{F}$ under $\hat{p}$. Note that $F_{n}(y)=1-p_{n}^{-1}(y)$. We show that $F_{n}(y) \rightarrow \hat{F}(y)$ for all $y$. Recall that $p_{n}$ is strictly decreasing. Fix $y$ and let $x=\hat{p}^{-1}(y)$. For any $\eta^{\prime}>0$ there exists $\eta \in\left(0, \eta^{\prime}\right)$ such that $p_{n}(x-\eta) \rightarrow \hat{p}(x-\eta)$ and $p_{n}(x+\eta) \rightarrow \hat{p}(x+\eta)$. For sufficiently large $n, p_{n}(x-\eta)>y$, and hence $p_{n}^{-1}(y)>x-\eta$. Similarly, $p_{n}(x+\eta)<y$ and hence $p_{n}^{-1}(y)<x+\eta$. Thus, $x-\eta<\lim _{n} p_{n}^{-1}(y)<$ $x+\eta$. Since this holds for all $\eta^{\prime}, \lim _{n} p_{n}^{-1}(y)=x=\hat{p}^{-1}(y)$.]

At almost all continuity points $\omega^{\prime}$ of $\hat{p}$, either inverse ex post demand is continuous at $\hat{p}\left(\omega^{\prime}\right)$ or inverse ex post supply is continuous at $\hat{p}\left(\omega^{\prime}\right)$, given $(\hat{L}, \hat{E})$ (or both). Let $\omega^{\prime}$ be a continuity point of $\hat{p}$ such that inverse ex post demand is continuous at $\hat{p}\left(\omega^{\prime}\right)$ and suppose there exists a subsequence of values of $n$ for which $\lim _{n \rightarrow \infty} p_{n}\left(\omega^{\prime}\right)>\hat{p}\left(\omega^{\prime}\right)$. [The cases of continuous inverse ex post supply and of $\lim _{n \rightarrow \infty} p_{n}\left(\omega^{\prime}\right)<\hat{p}\left(\omega^{\prime}\right)$ are analogous.] The inequality $\lim _{n \rightarrow \infty} p_{n}\left(\omega^{\prime}\right)>\hat{p}\left(\omega^{\prime}\right)$ and the continuity of inverse demand imply

$$
\lambda\left\{i \mid u\left(\hat{L}(i), \lim _{n \rightarrow \infty} p_{n}\left(\omega^{\prime}\right)\right)+(1-i) \geq u(\hat{L}(i), 0)\right\}<\lambda\left\{i \mid u\left(\hat{L}(i), \hat{p}\left(\omega^{\prime}\right)\right)+(1-i) \geq u(\hat{L}(i), 0)\right\},
$$

while we also have

$$
\lambda_{\varepsilon}\left\{j \mid v\left(\hat{E}(j), \lim _{n \rightarrow \infty} p_{n}\left(\omega^{\prime}\right)\right) \geq v(\hat{E}(j), 0)+j\right\} \geq \lambda_{\varepsilon}\left\{j \mid v\left(\hat{E}(j), \hat{p}\left(\omega^{\prime}\right)\right) \geq v(\hat{E}(j), 0)+j\right\} .
$$


Because $\hat{p}$ is an equilibrium price schedule, the right-hand sides of these two inequalities are equal. Hence, the convergence of $\left(L_{n}, E_{n}\right)$ to $(\hat{L}, \hat{E})$ ensures that for sufficiently large $n$, we have

$$
\lambda\left\{i \mid u\left(L_{n}(i), p_{n}\left(\omega^{\prime}\right)\right)+(1-i) \geq u\left(L_{n}(i), 0\right)\right\}<\lambda_{\varepsilon}\left\{j \mid v\left(E_{n}(j), p_{n}\left(\omega^{\prime}\right)\right) \geq v\left(E_{n}(j), 0\right)+j\right\},
$$

contradicting the requirement that $p_{n}\left(\omega^{\prime}\right)$ clear the ex post market given state $\omega^{\prime}$.

Now consider the second mapping $\Theta_{2}$. Suppose that $\mathcal{P}_{n}$ converges weakly to $\hat{\mathcal{P}}$. It suffices to show that $E_{n}(0)$ converges to the limit $\hat{E}(0)$ and that $\left(L_{n}, E_{n}\right)$ converge to $(\hat{L}, \hat{E})$ at continuity points of the latter, at which point Lebesgue's dominated convergence theorem gives convergence in norm. Consider $E_{n}(0)$. This value satisfies

$$
\max _{e \in[0, \bar{e}]} \int_{0}^{\bar{p}} v(e, p) d \mathcal{P}_{n}(p)
$$

giving first- and second-order conditions of

$$
\begin{aligned}
& \int_{0}^{\bar{p}} v_{1}(e, p) d \mathcal{P}_{n}(p)=0, \text { and } \\
& \int_{0}^{\bar{p}} v_{11}(e, p) d \mathcal{P}_{n}(p)<0 .
\end{aligned}
$$

The second-order condition is strictly negative, implying that $E_{n}(0)$ is unique. As $\mathcal{P}_{n}$ converges weakly to $\hat{\mathcal{P}}$, this objective function and first- and second-order conditions converge to (Patrick Billingsley, 1979, Theorem 29.1),

$$
\begin{aligned}
\max _{e \in[0, \bar{e}]} & \int_{0}^{\bar{p}} v(e, p) d \hat{\mathcal{P}}(p), \\
& \int_{0}^{\bar{p}} v_{1}(e, p) d \hat{\mathcal{P}}(p)=0, \text { and } \\
& \int_{0}^{\bar{p}} v_{11}(e, p) d \hat{\mathcal{P}}(p)<0,
\end{aligned}
$$

which has $\hat{E}(0)$ as its unique solution, ensuring that $E_{n}(0) \rightarrow \hat{E}(0)$. Next, let $i^{\prime}$ be a continuity point of $\hat{L}$. Then, $\hat{L}\left(i^{\prime}\right)$ and the optimal reservation price solve

$$
\max _{\ell, p^{\prime}} \int_{0}^{p^{\prime}}\left(u(\ell, p)+\left(1-i^{\prime}\right)\right) d \hat{\mathcal{P}}(p)+\int_{p^{\prime}}^{\bar{p}} u(\ell, 0) d \hat{\mathcal{P}}(p) .
$$

Suppose that $\lim _{n \rightarrow \infty} L_{n}\left(i^{\prime}\right)=\ell^{\prime} \neq \hat{L}\left(i^{\prime}\right)$. Because $i^{\prime}$ is a continuity point of $\hat{L}, \hat{L}\left(i^{\prime}\right)$ is the unique optimal choice of $\ell$ (Lemma 2) and so, for any reservation price $p^{\prime \prime}$, 


$$
\begin{aligned}
& \int_{0}^{p^{\prime \prime}}\left(u\left(\ell^{\prime}, p\right)+\left(1-i^{\prime}\right)\right) d \hat{\mathcal{P}}(p)+\int_{p^{\prime \prime}}^{\bar{p}} u\left(\ell^{\prime}, 0\right) d \hat{\mathcal{P}}(p) \\
& \quad<\max _{\ell, p^{\prime}} \int_{0}^{p^{\prime}}\left(u(\ell, p)+\left(1-i^{\prime}\right)\right) d \hat{\mathcal{P}}(p)+\int_{p^{\prime}}^{\bar{p}} u(\ell, 0) d \hat{\mathcal{P}}(p) .
\end{aligned}
$$

The weak convergence of $\mathcal{P}_{n}$ to $\hat{\mathcal{P}}$ and the convergence of $L_{n}\left(i^{\prime}\right)$ to $\ell^{\prime}$ then gives, for any reservation price $p^{\prime \prime}$ and for sufficiently large $n$ (Billingsley, 1979, Theorem 29.1),

$$
\begin{gathered}
\int_{0}^{p^{\prime \prime}}\left(u\left(L_{n}\left(i^{\prime}\right), p\right)+\left(1-i^{\prime}\right)\right) d \mathcal{P}_{n}(p)+\int_{p^{\prime \prime}}^{\bar{p}} u\left(L_{n}\left(i^{\prime}\right), 0\right) d \mathcal{P}_{n}(p) \\
\quad<\max _{\ell, p} \int_{0}^{p}\left(u(\ell, p)+\left(1-i^{\prime}\right)\right) d \mathcal{P}_{n}(p)+\int_{p}^{\bar{p}} u(\ell, 0) d \mathcal{P}_{n}(p),
\end{gathered}
$$

a contradiction to the optimality of $L_{n}\left(i^{\prime}\right)$. A similar argument applies to the seller, establishing the result.

\section{PROOF OF PROPOSITION 3:}

The proof of the first statement is an argument by contradiction. Suppose that $p_{\varepsilon}$ converges weakly to the constant function $\bar{p}$, for some $\bar{p}$.

Since the equilibrium price $p_{\varepsilon}$ is decreasing in $\omega$ (Lemma 7), we can (perhaps after relabelling the sequence) take a subsequence with the property that in economy $\varepsilon$,

$$
\bar{p}+\varepsilon>p_{\varepsilon}(\varepsilon) \geq p_{\varepsilon}(1-\varepsilon)>\bar{p}-\varepsilon .
$$

Hence, the price function $p_{\varepsilon}$ is squeezed within the band $(\bar{p}+\varepsilon, \bar{p}-\varepsilon)$ over the interval $[\varepsilon, 1-\varepsilon]$.

From Lemma 6, the inverse ex post supply and demand functions have at most countably many discontinuities. Hence, with probability one, the market price $p_{\varepsilon}(\omega)$ equals either the reservation price $p_{i(\omega)}\left(L_{i(\omega)}^{*}\right)$ of the marginal buyer $i(\omega)$ or the reservation price $p_{j(\omega)}\left(E_{j(\omega)}^{*}\right)$ of the marginal seller $j(\omega)$. Let $\mathcal{B}_{\varepsilon}$ be the set of states at which the market price is determined by a marginal buyer, and $S_{\varepsilon}$ be the set of states at which the market price is determined by a marginal seller. We have just argued that $\mathcal{B}_{\varepsilon} \cup S_{\varepsilon}$ is a full measure subset of [0,1]. Thus, for $\varepsilon<1 / 4$, there exists a pair of states $\omega$ and $\omega^{\prime}$ in $[\varepsilon, 1-\varepsilon]$ such that $\left|\omega-\omega^{\prime}\right| \geq 1 / 4$ and either $\omega, \omega^{\prime} \in \mathcal{B}_{\varepsilon}$ or $\omega, \omega^{\prime} \in S_{\varepsilon}$. By restricting attention to a subsequence, we can assume that the marginal agents are either always buyers, or always sellers, and moreover, that the sequence of pairs of marginal agents is convergent. Hence, considering the case in which the marginal agents are buyers, we have a sequence of pairs of buyers, $\left\{\left(i_{1}(\varepsilon), i_{2}(\varepsilon)\right)\right\}_{\varepsilon}$ with a corresponding sequence of pairs of states $\left\{\left(\omega_{1}(\varepsilon), \omega_{2}(\varepsilon)\right)\right\}_{\varepsilon}$ such that $i_{k}(\varepsilon)$ is the marginal buyer in state $\omega_{k}$, $k=1$ and 2:

$$
\begin{aligned}
& p_{\varepsilon}\left(\omega_{1}(\varepsilon)\right)=p_{i_{1}(\varepsilon)}\left(L_{i_{1}(\varepsilon)}^{*}\right), \text { and } \\
& p_{\varepsilon}\left(\omega_{2}(\varepsilon)\right)=p_{i_{2}(\varepsilon)}\left(L_{i_{2}(\varepsilon)}^{*}\right) .
\end{aligned}
$$

We normalize so that $i_{1}(\varepsilon)<i_{2}(\varepsilon)$. This implies 


$$
\begin{gathered}
\omega_{1}(\varepsilon)+\frac{1}{4}<\omega_{2}(\varepsilon), \text { and } \\
p_{\varepsilon}\left(\omega_{1}(\varepsilon)\right)>p_{\varepsilon}\left(\omega_{2}(\varepsilon)\right) .
\end{gathered}
$$

The weak convergence of the price function implies (through (A7))

$$
\left|p_{i_{1}(\varepsilon)}\left(L_{i_{1}(\varepsilon)}^{*}\right)-p_{i_{2}(\varepsilon)}\left(L_{i_{2}(\varepsilon)}^{*}\right)\right|<2 \varepsilon \text {. }
$$

Since buyers $i_{1}(\varepsilon)$ and $i_{2}(\varepsilon)$ trade at their reservation prices in states $\omega_{1}(\varepsilon)$ and $\omega_{2}(\varepsilon)$ (respectively) and $p_{\varepsilon}(\omega)$ is strictly decreasing, it must be that buyer $i_{1}(\varepsilon)$ trades with a probability that exceeds the probability with which $i_{2}(\varepsilon)$ trades by at least one-quarter [because buyer $i_{1}(\varepsilon)$ - but not buyer $i_{2}(\varepsilon)$-trades in states $\left.\left[\omega_{1}(\varepsilon), \omega_{2}(\varepsilon)\right)\right]$. We use this fact to show that the two buyers choose different investments. In particular, the optimal investments $L_{i_{1}(\varepsilon)}^{*}$ and $L_{i_{2}(\varepsilon)}^{*}$ solve, respectively:

$$
\begin{aligned}
\max _{\ell} & \int_{0}^{\omega_{1}(\varepsilon)} u(\ell, 0) d \omega+\int_{\omega_{1}(\varepsilon)}^{\omega_{2}(\varepsilon)}\left(u\left(\ell, p_{\varepsilon}(\omega)\right)+\left(1-i_{1}(\varepsilon)\right)\right) d \omega \\
+ & \int_{\omega_{2}(\varepsilon)}^{1}\left(u\left(\ell, p_{\varepsilon}(\omega)\right)+\left(1-i_{1}(\varepsilon)\right)\right) d \omega
\end{aligned}
$$

and

$$
\max _{\ell} \int_{0}^{\omega_{1}(\varepsilon)} u(\ell, 0) d \omega+\int_{\omega_{1}(\varepsilon)}^{\omega_{2}(\varepsilon)} u(\ell, 0) d \omega+\int_{\omega_{2}(\varepsilon)}^{1}\left(u\left(\ell, p_{\varepsilon}(\omega)\right)+\left(1-i_{2}(\varepsilon)\right)\right) d \omega
$$

As a result, there exists $\xi>0$ such that

$$
L_{i_{1}(\varepsilon)}^{*}-L_{i_{2}(\varepsilon)}^{*} \geq \xi \text { as } \varepsilon \rightarrow 0 .
$$

This follows from the observation that, conditioning on $\omega_{1}(\varepsilon)$ and $\omega_{2}(\varepsilon)$, the maximands in (A9)-(A10) are strictly concave in $\ell$ and hence yield unique maximizers. The disparity in middle terms [reflecting the fact that $i_{1}(\varepsilon)$ buys a house in states $\left[\omega_{1}(\varepsilon), \omega_{2}(\varepsilon)\right)$ while $i_{2}(\varepsilon)$ does not] ensures that (A9) has a positive derivative when the derivative of (A10) is zero, and hence $L_{i_{1}(\varepsilon)}^{*}-L_{i_{2}(\varepsilon)}^{*}>$ 0 , with the convergence of $\omega_{1}(\varepsilon)$ and $\omega_{2}(\varepsilon)$ to different limits and the weak convergence of prices ensuring that this difference does not converge to zero.

There then exists $\zeta>0$ such that

$$
p_{i_{1}(\varepsilon)}\left(L_{i_{1}(\varepsilon)}^{*}\right)-p_{i_{2}(\varepsilon)}\left(L_{i_{2}(\varepsilon)}^{*}\right) \geq \zeta
$$

This follows from the observation that the reservation price $p_{i}(\ell)$ is strictly increasing in $\ell$ and decreasing in $i$ (Lemma 5). But this contradicts (A8). Equivalently, since these buyers trade at their reservation prices when they are marginal, this implies

$$
p\left(\omega_{1}(\varepsilon)\right)-p\left(\omega_{2}(\varepsilon)\right) \geq \zeta>0
$$

a contradiction to the weak convergence of prices. 


\section{REFERENCES}

Allen, Franklin and Gale, Douglas. "Financial Fragility, Liquidity and Asset Prices." Financial Institutions Center Working Paper No. 01-37-B, University of Pennsylvania, 2003.

Billingsley, Patrick. Probability and measure, 1st Ed. New York: John Wiley \& Sons, 1979.

Dunford, Nelson and Schwartz, Jacob T. Linear operators. Part I: General theory. New York: Wiley-Interscience, 1988.

Grossman, Sanford J. and Hart, Oliver D. "The Costs and Benefits of Ownership: A Theory of Vertical and Lateral Integration." Journal of Political Economy, August 1986, 94(4), pp. 691-719.

Kübler, Felix and Polemarchakis, Herakles. "Sta- tionary Markov Equilibria for Overlapping Generations." Economic Theory, October 2004, 24(3), pp. 623-43.

Manuelli, Rodolfo and Peck, James. "SunspotLike Effects of Random Endowments." Journal of Economic Dynamics and Control, April 1992, 16(2), pp. 193-206.

Milgrom, Paul and Segal, Ilya. "Envelope Theorems for Arbitrary Choice Sets." Econometrica, March 2002, 70(2), pp. 583-601.

Shiller, Robert J. The new financial order: Risk in the 21st century. Princeton, NJ: Princeton University Press, 2003.

Shiller, Robert J. and Weiss, Allan N. "Home Equity Insurance." Journal of Real Estate Finance and Economics, July 1999, 19(1), pp. 21-47. 